\title{
ECONOMIC ANALYSIS OF FUNCTIONING OF THE OREL REGION GRAIN MARKET
}

\author{
ЭКОНОМИЧЕСКИЙ АНАЛИЗ ФУНКЦИОНИРОВАНИЯ РЫНКА ЗЕРНА \\ ОРЛОВСКОЙ ОБЛАСТИ
}

\section{A. Altukhov, Post-graduate Student}

А.В. Алтухов, аспирант

\section{Orel State Agrarian University, Orel City, Russia}

Орловский государственный аграрный университет, г. Орёл, Россия

Phone: +7 (4862) 45-37-64, E-mail: invest@,orelsau.ru

Received March 19, 2012

\begin{abstract}
АННОТАЦИЯ
Проанализировано производство и реализация зерна в Орловской области, дана оченка рыночной конъюнктуре рынка зерна, обоснованы факторы сдерживающие развитие рынка зерна в регионе. Отмечено заметное влияние агрофирм и холдингов на формирование в Орловской области предложения на рынке зерна. Доля посевных площадей данных формирований в общей площади посева зерновых составляет более $20 \%$. При этом переработка зерна практически полностью монополизирована, что создает объективные трудности по доведению агропродукиии до объектов назначения.
\end{abstract}

\begin{abstract}
In article analyzed the production and sale of grain in the Orel region, assess the market conditions of the grain market, justified factors constraining the development of the grain market in the region. Also impact on the firms and the holding companies in the Orel region is noted in supply of grain. The share of acreage data units in the total area sown grain is more than $20 \%$. At the same time refining the grain is almost completely monopolized, which creates inherent difficulties in bringing agricultural products to the destination object.
\end{abstract}

КЛЮЧЕВЫЕ СЛОВА

Зерно; Рынки; Маркетинг; Орловская область; Производство.

KEY WORDS

Grain; Markets; Marketing; Orel Region; Production.

Эффективное ф функционирование сельского хозяйства возможно лишь при развитом рынке сельскохозяйственной продукции. Ключевыми факторами развития рынка возможно лишь при предсказуемом объеме производства и продажи продукции, прогнозируемом спросе, ценах, удовлетворяющих как производителей, так и переработчиков. Рынок зерна обладает определенными особенностями, связанными с товарными свойствами зерна. Возможность длительного хранения зерна, без потери его товарных свойств, позволяет производителям управлять предложением во времени. В Орловской области возделывание зерновых культур является ключевой отраслью сельского хозяйства. Так, в 2010 году продажа зерна сформировала $63,5 \%$ выручки полученной от продажи продукции растениеводства. Экстенсивным фактором, оказывающим непосредственное влияние на объем производства зерна, является площадь посева. Данный фактор зависит лишь от условий хозяйствования аграрных предприятий. Каждое предприятие самостоятельно решает, ка- 
кими культурами и на каких площадях засеять свои земельные угодья. Следует отметить, что в последние годы площадь посева зерновых культур не снижается. В 2010 году площадь посева зерновых куль- тур составила 72,6\% всей посевной площади. В табл. 1 представлена динамика площади посева зерновых культур с 2000 по 2010 гг.

Таблица 1 - Динамика площади посевов зерновых культу в Орловской области, тыс. га

\begin{tabular}{|c|c|c|c|c|c|c|}
\hline Культуры & $2006 \Gamma$ & $2007 \Gamma$ & $2008 \Gamma$ & $2009 \Gamma$ & $2010 \Gamma$ & $2010 / 2006, \%$ \\
\hline Вся посевная площадь & 996,0 & 957,9 & 1025,8 & 1082,5 & 1076,5 & 108,1 \\
\hline Зерновые культуры - всего & 640,2 & 629,4 & 746,9 & 796,2 & 781,8 & 122,1 \\
\hline озимые зерновые культуры & 199,4 & 214,9 & 337,9 & 407,0 & 436,6 & 219,0 \\
\hline яровые зерновые культуры & 440,7 & 414,5 & 409,0 & 389,2 & 345,2 & 78,3 \\
\hline
\end{tabular}

Следует заметить, что произошли изменения в структуре посевов зерновых. Если до 2008 года яровые зерновые занимали в Орловской области более половины посевов зерновых культур, то начиная с 2009 года озимые культуры составляют большую часть посевов. Причем свыше 90\% посев озимых культур представляет собой озимая пшеница. Рожь сеют лишь в северо-западных районах Орловской области.

Характеризуя производителей зерна в Орловской области следует отметить, что основная доля производится сельскохозяйственными предприятиями. Они засевают 78\% всех посевных площадей зерновых. В результате преобразований последних лет в сельском хозяйстве наблюдается процесс становления сектора фермерских хозяйств, который по объемам производства хотя и остается небольшим, но позволяет вести предпринимательскую деятельность наиболее активной части сельского населения. Развитие подсобных хозяйств повышает уровень самообеспечения населения продуктами питания, что способствует сохранению социальной стабильности. Доля крестьянскофермерских хозяйств в структуре посевов составляет 20\%. В личных подсобных хозяйствах населения зерно практически не возделывается. Данная ситуация связана с тем, что зернопроизводство высоко технологично и энергоёмко. Оно требует наличие специального оборудования. Особенностью производства зерна является четкая последовательность выполнения ограниченных по времени стадий производства, таких как подготовка почвы, сев, обработка посевов, уборка урожая. Для каждой из этих стадий производства существует отдельный комплекс машин и оборудования. Одна из самых трудоемких и ответственных стадий производства зерна - уборка урожая. На сего- дняшний день применение комбинированных агрегатов для осуществления этого процесса экономически оправданно. Использование данной техники позволяет в сжатые сроки, с малыми потерями осуществлять практически весь спектр работ по уборке урожая. При производстве зерна используются следующие виды техники: тракторы (тягловая сила для большинства видов сельскохозяйственной техники), машины для подготовки почвы (плуги, культиваторы), техника для обработки посевов (опрыскиватели, разбрасыватели), уборочная техника (на современном этапе комбинированные агрегаты- комбайны). Весь этот набор техники необходим для производства зерна в комплексе. Современный уровень механизации сельскохозяйственного производства позволяет получать высокие урожаи этих культур и относительно низкой себестоимости. Поэтому в регионе проблемы оснащенности сельскохозяйственной техникой и эффективности ее использования имеют особую значимость, а рынок техники является ключевым звеном повышения эффективности сельскохозпроизводства.

В целом оснащение зернопроизводства Орловской области техникой характеризуется отрицательной динамикой. В табл. 2 представлены данные о наличии сельскохозяйственной техники в рассматриваемом регионе.

Как наглядно видно из табл. 2 количество сельскохозяйственной техники для производства зерна в хозяйствах Орловской области за период с 2000 по 2010 год снизилось, что привело к росту нагрузки на её единицу. Однако считаем данный факт естественным процессом, так как современная техника, представленная на рынке обладает значительно более высокой производительностью. 


\section{A. ALTUKHOV, Orel State Agrarian University}

Таблица 2 - Оценка обеспеченности производства зерна в Орловской области сельскохозяйственной техникой*

\begin{tabular}{|c|c|c|c|c|c|c|}
\hline Вид техники & 2006 г. & 2007 г. & 2008 г. & 2009 г. & $2010 г$. & $2010 / 2006, \%$ \\
\hline Зерноуборочные комбайны & 1978 & 1561 & 1415 & 1244 & 1207 & 61,0 \\
\hline Тракторы & 5644 & 4732 & 4375 & 3965 & 3797 & 67,3 \\
\hline Плуги тракторные & 1880 & 1572 & 1431 & 1287 & 1216 & 64,7 \\
\hline Культиваторы & 2623 & 2376 & 2212 & 1985 & 1896 & 72,3 \\
\hline Сеялки & 2018 & 1607 & 1362 & 1291 & 1196 & 59,3 \\
\hline $\begin{array}{l}\text { Приходится посевов зерновых на } \\
\text { один комбайн, га }\end{array}$ & 251 & 294 & 381 & 445 & 459 & 182,9 \\
\hline Нагрузка пашни на один трактор, га & 184 & 199 & 219 & 232 & 283 & 153,8 \\
\hline
\end{tabular}

* http://orel.gks.ru

Это подтверждается тем фактом, что снижение количества техники не влечет за собой снижение площадей посева культур. Следует отметить заметное влияние на формирование в Орловской области предложения на рынке зерна агрофирм и холдингов. Доля посевных площадей данных формирований в общей площади посева зерновых составляет почти $20 \%$. Отметим, что техническое оснащение производства зерна в интегрированных структурах значительно выше чем в средних и малых предприятиях. При этом переработка зерна практически полностью монополизирована, что создает определенные трудности по доведению агропродукции до объекта назначения. Кроме того, наряду с крупными торговыми компаниями функционируют сотни мелких и средних частных посредников, обеспечивающих продвижение про- дукции до потребителей. Следует указать, что рынок зерна в Орловской области высоко конкурентен. Это связано, что практически все сельскохозяйственные предприятия возделывают зерновые культуры примерно одинакового качества. На рынке этих видов продукции борьба за эффективность продаж сводиться к снижению себестоимости. В тоже время цены на эти виды сельскохозяйственной продукции диктуется заготовителями, поэтому для увеличения продаж сельскохозяйственные производители идти на определенные уступки.

На объем производства зерна и его качество оказывает влияние ряд факторов, таких как качество почвы, погодные условия, технология и т.д. В табл. 3 представлена динамика урожайности зерновых культур в Орловской области.

Таблица 3 - Урожайность зерновых культур в Орловской области*

\begin{tabular}{|c|c|c|c|c|c|c|}
\hline Культуры & 2006 г. & 2007 г. & 2008 г. & 2009 г. & 2010 г. & $2010 / 2006, \%$ \\
\hline Зерновые культуры (в весе после доработки) & 24,1 & 23,0 & 31,4 & 30,7 & 21,6 & 89,6 \\
\hline в т.ч.: пшеница озимая & 28,1 & 31,3 & 34,2 & 35,1 & 25,0 & 89,0 \\
\hline рожь озимая & 17,4 & 24,1 & 27,8 & 25,4 & 19,6 & 112,6 \\
\hline пшеница яровая & 24,9 & 18,7 & 29,2 & 31,9 & 17,7 & 71,1 \\
\hline ячмень яровой & 25,9 & 21,1 & 32,7 & 29,9 & 18,8 & 72,6 \\
\hline овес & 18,1 & 20,3 & 27,8 & 24,0 & 17,9 & 98,9 \\
\hline гречиха & 7,7 & 8,2 & 10,3 & 10,4 & 4,9 & 63,6 \\
\hline
\end{tabular}

* http://orel.gks.ru

Урожайность зерновых культур в целом по Орловской области за рассматриваемый период имеет тенденцию к снижению (табл.3). Так, в 2010 г. по сравнению с 2006 г. данный показатель снизился на $10,4 \%$, в тоже время по сравнению с предыдущим годом более значительное снижение - на 29,6\%.

Валовой сбор зерновых за рассматриваемый период во всех категориях хозяйств области так же увеличился (табл. 4). Однако в 2010 г. по сравнению с 2009 г. данный показатель снизился почти на половину, что связано было с резким падением урожайности в результате засухи. В тоже время данные погодные условия незначительно сказались на валовом сборе зерна в личных подсобных хозяйствах населения. 
Таблица 4 - Валовой сбор продуктов растениеводства в хозяйствах всех категорий Орловской области (тысяч тонн)

\begin{tabular}{|c|c|c|c|c|c|c|}
\hline Культуры & 2006 г. & $2007 \Gamma$. & $2008 \Gamma$ & $2009 \Gamma$. & $2010 \Gamma$. & $2010 / 2006, \%$ \\
\hline Зерно, в т.ч.: & 1276,8 & 1353,6 & 2282,3 & 2393,1 & 1507,8 & 118,1 \\
\hline пшеница озимая & 436,6 & 601,2 & 1021,2 & 1281,4 & 1019,5 & 233,5 \\
\hline рожь озимая & 50,9 & 50,8 & 89,1 & 72,8 & 36,8 & 72,3 \\
\hline пшеница яровая & 192,5 & 130,4 & 127,8 & 151,6 & 101,8 & 52,9 \\
\hline ячмень яровой & 509,0 & 458,3 & 842,7 & 690,9 & 251,2 & 49,4 \\
\hline овес & 35,2 & 51,0 & 75,0 & 52,2 & 29,3 & 83,2 \\
\hline гречиха & 29,5 & 38,5 & 45,1 & 62,8 & 17,0 & 57,6 \\
\hline
\end{tabular}

Рост валового сбора зерна естественно влияет на конъюнктуру рынка. Укажем, что спрос на данный вид сельскохозяйственной продукции в Орловской области довольно высок, однако колебания валового сбора оказывают существенное влияние на цену.

Укажем, что отсутствие должно, на наш взгляд, регулирование рынка зерна и рынка удобрений и техники приводит к значительному снижению эффективности сельскохозяйственного производства.

Анализ структуры себестоимости зерна позволяет наглядно отразить те статьи расходов, которые формируют основную долю затрат (табл. 5).

Таблица 5 - Состав и структура себестоимости 1 ц зерна

\begin{tabular}{|c|c|c|c|c|c|c|c|c|}
\hline \multirow[t]{2}{*}{ Статьи затрат } & \multicolumn{2}{|c|}{$\begin{array}{c}\text { В среднем } \\
\text { за год } 1996- \\
2000 \text { гг. }\end{array}$} & \multicolumn{2}{|c|}{2008 г. } & \multicolumn{2}{|c|}{2009 г. } & \multicolumn{2}{|c|}{2010 г. } \\
\hline & руб. & $\begin{array}{c}\text { в \% } \\
\text { к итогу }\end{array}$ & руб. & $\begin{array}{c}\text { в \% } \\
\text { к итогу }\end{array}$ & руб. & $\begin{array}{c}\text { в \% } \\
\text { к итогу }\end{array}$ & руб. & $\begin{array}{c}\text { в \% } \\
\text { к итогу }\end{array}$ \\
\hline Себестоимость 1 ц, всего, в т.ч. & 66,9 & 100,0 & 313,2 & 100,0 & 317,8 & 100,0 & 447,9 & 100,0 \\
\hline - оплата труда с отчислениями & 7,6 & 11,4 & 32,5 & 10,4 & 37,1 & 11,7 & 49,2 & 11,0 \\
\hline - семена и посадочный материал & 9,9 & 14,8 & 38,9 & 12,4 & 38,8 & 12,2 & 47,5 & 10,6 \\
\hline - удобрения & 9,3 & 13,9 & 51,1 & 16,3 & 52,1 & 16,4 & 79,2 & 17,7 \\
\hline - химические средства защиты & - & - & 20,8 & 6,6 & 20,6 & 6,5 & 32,5 & 7,3 \\
\hline - электроэнергия & - & - & 2,7 & 0,9 & 2,8 & 0,9 & 3,5 & 0,8 \\
\hline - нефтепродукты & - & - & 37,6 & 12,0 & 33,8 & 10,6 & 39,7 & 8,9 \\
\hline - затраты на страхование & - & - & - & - & - & - & 1,3 & 0,3 \\
\hline - содержание основных средств & 24,8 & 37,0 & 63,2 & 20,2 & 66,7 & 21,0 & 95,6 & 21,3 \\
\hline
\end{tabular}

Как видно из представленного материала основную долю в затратах на производство зерна занимают удобрения и содержание основных средств, то есть затраты на приобретаемые ресурсы. Также отметим тенденцию роста удельных затрат на средства защиты растений. Результаты конечной финансовой и экономической деятельности сельскохозяйственных организаций во многом определяются объемами и качеством реализованной продукции. Последняя выступает мерилом богатства и благополучия не только сельского хозяйства, но и других отраслей и производств агропромышленного комплекса.

Таблица 6- Реализация зерновых культур сельскохозяйственными организациями Орловской области

\begin{tabular}{|l|c|c|c|c|c|c|}
\hline \multicolumn{1}{|c|}{ Показатели } & 2006 г. & 2007 г. & 2008 г. & 2009 г. & 2010 г. & $2010 / 2006, \%$ \\
\hline Объем реализации зерновых, тыс. тонн & 862,8 & 818,2 & 999,3 & 1620,4 & 1308,3 & 151,6 \\
\hline $\begin{array}{l}\text { Полная себестоимость проданной продук- } \\
\text { ции, тыс. руб. }\end{array}$ & 2220060 & 2583082 & 2911418 & 4803018 & 4845876 & 218,3 \\
\hline Денежная выручка, тыс. руб. & 2432159 & 3612154 & 3703979 & 4726079 & 5257079 & 216,1 \\
\hline Прибыль (убыток) от реализации, тыс. руб. & 212099 & 1029072 & 792561 & -76939 & 411203 & 193,9 \\
\hline
\end{tabular}


Анализируя табл. 6 необходимо отметить устойчивую тенденцию наращивания объемов реализуемых зерновых культур в Орловской области. В целом за рассматриваемый период его количество увеличилось более чем в 2 раза, однако, в связи с действием неблагоприятных погодных условий в 2010 г. по сравнению с 2009 г. произошло резкое падение объемов реализации зерна на 17,8\%.

Помимо емкости рынка, существенное влияние на перспективы развития сельскохозяйственных рынков оказывают технологические мощности для хранения и переработки сельскохозяйственной продукции. Естественно, приоритет на данном рынке принадлежит предприятиям по хранению и переработке сельскохозяйственной продукции, они и диктуют цены. Необходимость хранения зерна обусловлена и сезонностью производства данной культуры и непрерывностью ее потребления. Хранение зерна в Орловской области организовано на 20 организациях элеваторного комплекса, к которому относятся элевато- ры, хлебоприемные предприятия, комбинаты хлебопродуктов, комбикормовые заводы, хлебные базы. Общий объем емкостей для хранения зерна в 2010 г. составляет 916,6 тыс.т.

Данные условия порождают ряд проблем, сдерживающих развитие рынка зерна в регионе:

1. низкие денежные доходы от реализации продукции из-за низкого уровня цен на нее и ограниченный сбыт;

2. межотраслевой диспаритет цен и доходов. Ценовое давление со стороны посредников и перекупщиков привело к многократному снижению доли сельскохозяйственных товаропроизводителей в розничной цене конечного продукта;

3. отсутствие эффективных систем регулирования рынков, а также наличие торговых барьеров между регионами, искусственное сдерживание цен;

4. слабое развитие рыночной инфраструктуры, которая не обеспечивает полное удовлетворение потребителей аграрной продукцией по приемлемым ценам.

\section{БИБЛИОГРАФИЯ}

Драгайцев В.И и др. Методика экономической оценки технологий и машин в сельском хозяйстве /, Алексеев К.И., Марюхненко Ж.С., Мирошников Г.А., Полухин А.А., Алпатов А.В., Грудкин А.А., Ставцев А.Н., Жуков Н.И., Новиков Ю.И. - Москва 2010. 147 c.

Закон Орловской области №731-О3 от 6 декабря 2007 года «Об областной целевой программе «Развитие сельского хозяйства и регулирование рынков сельскохозяйственной продукции, сырья и продовольствия на 2008-2012 годы».

Кошолкина А.А., 2008 - Развитие системы государственной поддержки АПК / А.А.Кошолкина // Экономика сельскохозяйственных и перерабатывающих предприятий. - 2008. №10.
Орловская область в цифрах: сельское хозяйство [Электронный ресурс]. Режим доступа: http://orel.gks.ru.

Полухин А.А., Ставцев А.Н. Формирование технической базы для освоения ресурсосберегающих технологий в зернопроизводстве // Вестник ОрёлГАУ. 2008. №6. С. 23-26.

Хлусов В.П., 2008 - Государственное регулирование агропромышленного рынка / В. П. Хлусов // Экономика сельскохозяйственных и перерабатывающих предприятий. - 2008 . - №6.

Шибайкин А.В., 2009 - Совершенствование государственной поддержки агропроизводственной сферы региона / А. В. Шибайкин // Экономика сельскохозяйственных и перерабатывающих пред-приятий. - 2009. №4. 